\title{
Lateral mixing in trickle bed reactors
}

\author{
B.V. Babu ${ }^{\mathrm{a}, *}$, K.J. Shah ${ }^{\mathrm{b}}$, V. Govardhana Rao ${ }^{\mathrm{c}}$ \\ ${ }^{a}$ Birla Institute of Technology and Science (BITS), Pilani 333 031, Rajasthan, India \\ bIBM Global Services-Vevey, Switzerland \\ ${ }^{\mathrm{c}}$ Chemical Engineering Department, Indian Institute of Technology (IIT)-Bombay, Powai, Mumbai 400 076, Maharashtra, India
}

\begin{abstract}
Knowledge of lateral mixing is essential to understand heat and momentum transfer parameters in both single-phase liquid and two-phase gas-liquid co-current down flow through packed bed columns. The reactors through which gas and liquid concurrently flow downwards through a bed of catalytic packing are called trickle bed reactors. Experimental data on lateral mixing coefficients from both the heat transfer and radial liquid distribution studies are obtained over a wide range of flow rates of gas $\left(0.01-0.898 \mathrm{~kg} / \mathrm{m}^{2} \mathrm{~s}\right)$ and liquid $\left(3.16-71.05 \mathrm{~kg} / \mathrm{m}^{2} \mathrm{~s}\right) \mathrm{using}$ glass spheres $(4.05$ and $6.75 \mathrm{~mm})$, ceramic spheres $(2.59 \mathrm{~mm})$, and ceramic raschig rings $(4$ and $6.75 \mathrm{~mm})$ as packing materials covering trickle flow, pulse flow, and dispersed bubble flow regimes. In the present work, an expression for estimation of lateral mixing coefficient $(\alpha \beta)_{L}$ is derived using the data on radial liquid distribution studies. The agreement between the values of $(\alpha \beta)_{L}$ obtained from heat transfer studies and from radial liquid distribution studies using the experimental data shows that there exists an analogy between the heat transfer and radial liquid distribution in packed beds. Since $(\alpha \beta)_{L}$ is an important variable for estimation of various heat and mass transfer parameters, a correlation for $(\alpha \beta)_{L}$ based on present heat transfer study is proposed. The agreement between the $(\alpha \beta)_{L}$ values estimated from the proposed correlation and experimental values is satisfactory with a standard deviation (s.d.) of 0.119 .
\end{abstract}

Keywords: Trickle bed reactor; Heat transfer; Mixing; Packed bed; Mass transfer; Dispersed bubble flow; Liquid distribution; Lateral mixing

\section{Introduction}

Lateral mixing is an important aspect in understanding the heat and momentum transfer parameters in both single-phase liquid and two-phase gas-liquid co-current down flow through packed bed columns. Lateral mixing coefficient of liquid and gas are widely used for estimating the heat transfer parameters, the effective radial thermal conductivity of the bed $\left(k_{e r}\right)$, wall to bed heat transfer coefficient $\left(h_{w}\right)$ and Peclet number of heat and mass transfer $\left(P e_{H}\right.$ and $\left.P e_{M}\right)$ (Matsuura et al., 1979; Hashimoto et al., 1976; Specchia and Baldi, 1979; Specchia et al., 1980). A trickle bed reactor (TBR) consists of a packed bed with gas and liquid flowing co-currently downwards. The aspects of hydrodynamics (flow patterns, pressure drop, hold up, etc.) in TBRs were extensively studied, and Satterfield (1975), Charpentier (1976), Gianetto et al. (1978), Shah (1979), Herskowitz and Smith (1983), and Larachi et al. (2003) summarized in their review articles. Various flow regimes are encountered in TBR depending upon the flow rates of the fluids: the gas-continuous or trickle flow (TF) at low liquid and gas rates, pulse flow (PF) at intermediate liquid and gas rates, liquid continuous or dispersed bubble flow (DBF) at higher liquid rates. TBR finds wide applications in petroleum industries, chemical and pharmaceutical industries, and in waste-water treatment. Industrial TBRs are usually operated in trickle and PF regimes (Satterfield, 1975; Blok and Drinkenburg, 1982; Sato et al., 1973). Heat transfer parameters are essential in the pseudohomogeneous model equation which is used for the design of TBRs.

Lateral mixing is generally expressed in terms of lateral mixing co-efficient, $(\alpha \beta)$ in single-phase flow and $(\alpha \beta)_{L}$ and $(\alpha \beta)_{G}$ 
for liquid and gas, respectively, in two-phase flow where $\alpha$ is the fraction of fluid mass velocity moving radially through each of the $N$-planes in a packed bed; and $\beta$ is defined as $l_{p} / d_{p}$. The heat transfer parameters, $k_{e r}$ and $h_{w}$, are generally expressed in terms of lateral mixing coefficients. Ranz (1952) was the first to propose a model for lateral mixing contribution by considering the bed to be composed of $N$ number of planes interconnected radially, whose dimensions and spacings are determined by the size and shape of the particles and the geometry of the packing. Later, Yagi and Kunii (1957) proposed a model for an average effective radial thermal conductivity of the packed bed as being contributed by stagnant and lateral mixing components for single-phase flow. Subsequently, Yagi and Kunii model was extended to two-phase flow through packed beds also (Hashimoto et al., 1976; Matsuura et al., 1979; Specchia and Baldi, 1979; Babu, 1993; Babu and Sastry, 1999; Babu and Rao, 2007).

The radial liquid distribution in TBR depends on the liquid and gas flow rates, the physical properties of the phases, the design of gas-liquid distributor and the type and size of the packing material employed. A few studies have been reported in literature on lateral liquid dispersion and empirical correlations have been proposed for predicting the radial dispersion of liquid (Lutran et al., 1991; Marcandelli et al., 2000; Boyer et al., 2005). It is interesting to know if there exists an analogy between heat and momentum transfer in radial spread of the liquid in TBRs. It would be useful to get the lateral mixing coefficient of heat transfer by analogy through momentum transfer studies, as it is difficult to measure the former values. In the present work an attempt is made to bring out the heat and momentum transfer analogy for lateral mixing co-efficient based on the experimental data on heat transfer (Babu, 1993) and radial liquid distribution (Babu et al., 1991) studies on trickle bed columns.

\section{Estimation of $(\alpha \beta)_{L}$ from heat transfer data}

\subsection{Experimental}

The radial liquid distribution and heat transfer data on singlephase liquid and two-phase gas-liquid co-current down flow through packed bed columns were measured experimentally in a $50 \mathrm{~mm}$ diameter and $1100 \mathrm{~mm}$ length column using packings shown in Table 1. The experiments were carried out over a wide range of flow rates of air $\left(0.01-0.898 \mathrm{~kg} / \mathrm{m}^{2} \mathrm{~s}\right)$ and water $\left(3.16-71.05 \mathrm{~kg} / \mathrm{m}^{2} \mathrm{~s}\right)$ covering TF, PF and DBF regimes. Experiments were also carried out for single-phase heat transfer through packed beds by using water as the flowing fluid, and under wet-bed conditions using air as the fluid. The radial temperature profile was obtained by measuring the temperature at the bottom of the test section at four radial positions at $r / R=0$, $0.4,0.8$ and 1.0, and at three symmetric angular positions (at $120^{\circ}$ apart) for each radial position. The detailed description of the experimental setup for heat transfer studies were reported elsewhere (Babu and Sastry, 1999).

\subsection{Estimation of $k_{e r}$}

The two-dimensional pseudo-homogenous two-parameter model is widely used for describing heat transfer phenomena in packed beds (De Wasch and Froment, 1972; Tsang et al., 1976). For a constant wall temperature, the solution of the above model (De Wasch and Froment, 1972) is

$$
\frac{T-T_{i}}{T_{0}-T_{w}}=1-2 \sum_{n=1}^{\infty} \frac{J_{0}\left(b_{n} r / R\right) \exp \left(-A b_{n}^{2} Z\right)}{b_{n} J_{1}\left(b_{n}\right)\left[1+\left(b_{n} / B i\right)^{2}\right]},
$$

where $A$ and $B i$ are defined by Eqs. (2) and (3), respectively.

$A=\frac{k_{e r}}{R^{2}\left(L c_{p L}+G c_{p G}^{*}\right)}$,

$B i=$ Biot number $=\frac{h_{w} R}{k_{e r}}$,

$b_{n}$ are the roots of $\operatorname{BiJ}_{0}\left(b_{n}\right)=b_{n} J_{1}\left(b_{n}\right)$.

An optimization method was used for estimating $k_{e r}$ and $h_{w}$ from Eq. (1) using the measured radial temperature profile with an objective function defined as

$F=\sum_{1}^{M}\left(T_{\text {cal }}-T_{\text {exp }}\right)^{2}$

where $M$ is the number of temperature measurement points. $F$ was minimized, and optimum values of $k_{e r}$ and $h_{w}$ were obtained (Babu and Sastry, 1999).

\subsection{Estimation of $(\alpha \beta)_{L}$}

The effective radial bed thermal conductivity $k_{e r}$ is analyzed by extending the Yagi and Kunii (1957) model to two-phase flow, which was originally proposed for single-phase flow. For two-phase flow in packed beds, $k_{e r}$ is expressed as the sum of three terms as given by the following

$k_{e r}=k_{e 0}+\left(k_{e t}\right)_{G}+\left(k_{e t}\right)_{L}$.

According to Ranz (1952) and Yagi and Kunii (1957) models, the lateral mixing of the fluid can be written for the gas and liquid phases, respectively, as

$$
\begin{aligned}
& \left(k_{e t}\right)_{G}=(\alpha \beta)_{G} G c_{p G}^{*} d_{p}, \\
& \left(k_{e t}\right)_{L}=(\alpha \beta)_{L} L c_{p L} d_{p} .
\end{aligned}
$$

As liquid phase contribution was found to be more for $k_{e r}$ over a wide range of experimental conditions, the thermal conductivity of liquid, $k_{L}$ is chosen as a characteristic parameter to normalize Eq. (6). From Eqs. (6)-(8), we get

$\frac{k_{e r}}{k_{L}}=\frac{k_{e 0}}{k_{L}}+(\alpha \beta)_{G} \frac{G c_{p G}^{*} d_{p}}{k_{L}}+(\alpha \beta)_{L} \frac{L c_{p L} d_{p}}{k_{L}}$. 
Table 1

The geometric characteristics and the values of $k_{e 0}$ and $(\alpha \beta)_{G}$ of the packings

\begin{tabular}{|c|c|c|c|c|c|c|}
\hline S. no. & Packing & $D_{e}(\mathrm{~mm})$ & $\varepsilon$ & $a_{s}\left(\mathrm{~m}^{-1}\right)$ & $k_{e 0}(\mathrm{~W} / \mathrm{mK})$ & $(\alpha \beta)_{G}$ \\
\hline 1 & $6.75 \mathrm{~mm}$ ceramic raschig rings & 8.10 & 0.491 & 376.96 & 0.535 & 0.110 \\
\hline 2 & $4.0 \mathrm{~mm}$ ceramic raschig rings & 4.89 & 0.508 & 604.17 & 0.439 & 0.120 \\
\hline 3 & $2.59 \mathrm{~mm}$ ceramic spheres & 2.59 & 0.321 & 1572.97 & 0.577 & 0.111 \\
\hline 4 & $4.05 \mathrm{~mm}$ glass spheres & 4.05 & 0.370 & 932.88 & 0.511 & 0.112 \\
\hline 5 & $6.75 \mathrm{~mm}$ glass spheres & 6.75 & 0.389 & 542.93 & 0.554 & 0.131 \\
\hline
\end{tabular}

For estimation of $k_{e 0}$, thermal conductivities under wet-bed conditions were measured as a function of gas flow rate (Babu and Rao, 1998). With no liquid flow, Eq. (9) reduces to

$\frac{k_{e r}}{k_{L}}=\frac{k_{e 0}}{k_{L}}+(\alpha \beta)_{G} \frac{G c_{p G}^{*} d_{p}}{k_{L}}$.

$\left(k_{e r} / k_{L}\right)$ is plotted against $\left(G c_{p G}^{*} d_{p} / k_{L}\right)$ using the wet-bed results for each of the packings. The intercepts of these plots give the value of $\left(k_{e 0} / k_{L}\right)$, and the slopes give $(\alpha \beta)_{G} .(\alpha \beta)_{G}$ values under two-phase flow conditions were also estimated using Eq. (9), which is rearranged to give,

$\frac{k_{e r}-k_{e 0}}{G c_{p G}^{*} d_{p}}=(\alpha \beta)_{G}+(\alpha \beta)_{L} \frac{L c_{p L}}{G c_{p G}^{*}}$.

The experimental values at a given liquid rate follow a linear relation with a common intercept for various liquid rates. Similar trends were observed for other packings in all the flow regimes (Babu, 1993; Babu and Rao, 1998). This indicates that $(\alpha \beta)_{G}$ values are more or less constant and independent of liquid and gas rates. In fact, for single-phase flow the values of $(\alpha \beta)_{G}$ for different sizes and shapes of packings were reported to be ranging from 0.083 to 0.12 for spheres, and from 0.09 to 0.145 for cylinders, for $d_{p} / D_{t}$ ranging from 0.02 to 0.2 (Yagi et al., 1964). For two-phase gas-liquid down flow through packed beds, Hashimoto et al. (1976) reported $(\alpha \beta)_{G}$ value to be 0.095 for $4.8 \mathrm{~mm}$ glass spheres. The value of $(\alpha \beta)_{G}$ obtained using Eq. (10) ranges from 0.111 to 0.131 , and by using Eq. (11) ranges from 0.10 to 0.13 for different packings of present study. These results show that the value of $(\alpha \beta)_{G}$ estimated under wet-bed conditions and under two-phase flow conditions do not differ appreciably, and are in a very good agreement with the values reported in literature for similar packings (Yagi et al., 1964; Hashimoto et al., 1976). $(\alpha \beta)_{L}$ values were estimated from Eq. (8), by substituting the estimated values of $k_{e 0}$ and $(\alpha \beta)_{G}$, for various gas and liquid rates for different packings of present study. The estimated $(\alpha \beta)_{G}$ and $k_{e 0}$ values for various packings under study are shown in Table 1.

The following observations are made from the data on $(\alpha \beta)_{L}$ for different packings. $(\alpha \beta)_{L}$ decreases with increasing liquid rates in all the flow regimes. But the effect of particle diameter appears to be complex. $(\alpha \beta)_{L}$ increases with $d_{p}$ at low liquid and gas rates in TF regime and then decreases at high gas rates with increase in particle diameter from 2.59 to $4.05 \mathrm{~mm}$ spheres. For raschig rings, $(\alpha \beta)_{L}$ decreases with $d_{p}$, the rate of decrease being less at high liquid rates. Similar trends were also observed from the $(\alpha \beta)_{L}$ values evaluated from the correlations given by Hashimoto et al. (1976). The understanding of this complex behavior of $(\alpha \beta)_{L}$ with the particle size and shape probably requires more experimental data.

\section{Estimation of $(\alpha \beta)_{L}$ from radial liquid distribution studies}

\subsection{Experimental setup and procedure}

The schematic diagram of the experimental setup is shown in Fig. 1. The radial liquid distribution section at the bottom of the column consists of two parts made of Perspex tubes. The top part of the section is concentric annular liquid diverter, and the bottom part being the concentric annular collector. It consists of three transparent concentric Perspex tubes of 10,30 and $50 \mathrm{~mm}$ i.d., respectively, delimiting three zones, center, middle and wall. Taking into account of the thickness of the Perspex tube and the diameter of the column of $50 \mathrm{~mm}$ i.d., three sections are used. This also ensures the non-interference of measuring device on the measurements. There are 25 holes at the bottom of the diverter leading the liquid to the concentric annular liquid collector $(6 \mathrm{~mm}$ i.d. and $0.3 \mathrm{~mm}$ thick SS tubes were fixed to each hole; i.e., $16 \mathrm{SS}$ tubes in the wall section, 8 in the middle section and 1 in the center section. Air escapes through the SS tubes before the liquid entering the annular liquid collector. The upper edges of the annuli of the diverter were tapered to form sharp edges to minimize the contact area with bottom of the grid plate and to reduce the influence of the device on the flow distribution. The flow areas in the annular zones of the column and in the tubes of the liquid diverter were made approximately equal to avoid the flooding of liquid in the diverter. Air and liquid from test section flows out through annular liquid diverter, air gets separated and liquid comes down through the collector. After steadystate was reached, the flow rates of liquid in each of the three annular sections of the collector were measured in a given time. All the experiments were repeated three times and the average readings were taken at various water flow rates keeping the air flow rate constant. This procedure was repeated for different air flow rates. The reproducibility of the data was also cross-checked by conducting a few selected experiments by changing the air flow rate, keeping the liquid rate constant. The detailed description of the experimental setup and data generation is reported elsewhere (Babu et al., 1991). 


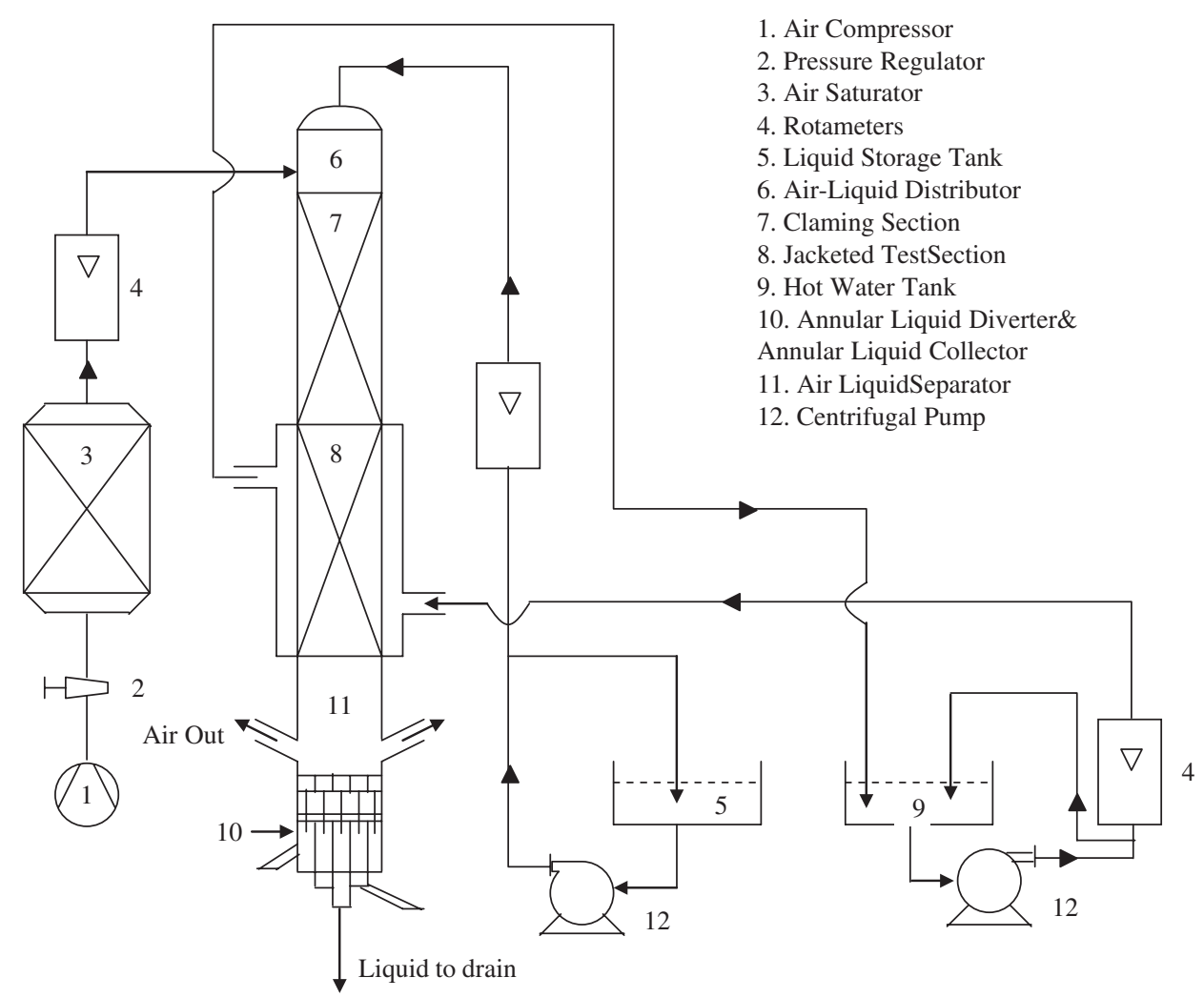

Fig. 1. Schematic diagram of experimental setup for radial liquid distribution studies.

\subsection{Estimation of $(\alpha \beta)_{L}$}

The cross-section of the packed column is divided into three sections. For central section the quantity of liquid coming out is $A_{1} \bar{L}_{1}$. For an uniform liquid distribution over the cross-section, quantity of liquid which should come out is $A_{1} \bar{L}$. So,

liquid spread in radial direction $=A_{1} \bar{L}-A_{1} \bar{L}$

$$
=A_{1}\left(\bar{L}_{1}-\bar{L}\right)
$$

fraction of liquid radial spread in the section,

$\alpha_{1}=\frac{A_{1}\left(\bar{L}_{1}-\bar{L}\right)}{3 A_{1} \bar{L}}=\frac{\left(\bar{L}_{1}-\bar{L}\right)}{3 \bar{L}}$.

Similarly, for the other two sections (middle and wall sections)

$\alpha_{2}=\frac{\left(\bar{L}_{2}-\bar{L}\right)}{3 \bar{L}} \quad$ and $\quad \alpha_{3}=\frac{\left(\bar{L}_{3}-\bar{L}\right)}{3 \bar{L}}$,

respectively.

Combining all the above equations and taking an average, we get the following relation for the overall radial spread of liquid,

$\alpha=\frac{1}{3} \sqrt{\frac{\left(\bar{L}_{1}-\bar{L}\right)^{2}+\left(\bar{L}_{2}-\bar{L}\right)^{2}+\left(\bar{L}_{3}-\bar{L}\right)^{2}}{9 \bar{L}^{2}}}$.

Then $(\alpha \beta)_{L}$ values obtained from heat transfer studies and radial liquid distribution studies are shown in Fig. 2. As can be seen from Fig. 2, the agreement between the heat transfer values and radial liquid distribution values is satisfactory. Most of the data points lie within the error limits of $\pm 20 \%$ with a standard deviation (s.d.) of 0.232 . The agreement between the $(\alpha \beta)_{L}$ values obtained from heat transfer and radial liquid distribution studies with a reasonable s.d. and within acceptable error limits shows that there exists an analogy for lateral mixing coefficients between heat and momentum transfer.

\section{Correlation for $(\alpha \beta)_{L}$ based on heat transfer experimental data}

As the agreement between the $(\alpha \beta)_{L}$ values obtained from heat transfer and radial liquid distribution studies is good, a correlation for $(\alpha \beta)_{L}$ is proposed based on heat transfer experimental data as follows:

$(\alpha \beta)_{L}=0.928\left[\frac{R e_{L}}{\varepsilon \beta_{t}}\right]^{-0.342}\left[\frac{\operatorname{Re}_{G}}{\varepsilon\left(1-\beta_{t}\right)}\right]^{-0.037}\left(a_{S}\right)^{0.008}$

$(\alpha \beta)_{L}$ decreases with both liquid and gas rates. But in the packed beds, the real liquid and gas flow rates are to be considered due to the presence of solid particles as packing media. In order to calculate the real liquid and gas flow rates in twophase flow through packed beds, in addition to the bed voidage the liquid holdup and gas holdup are also to be incorporated. The data on total liquid holdup $\left(\beta_{t}\right)$ for various packings of present study were also measured experimentally by residence 


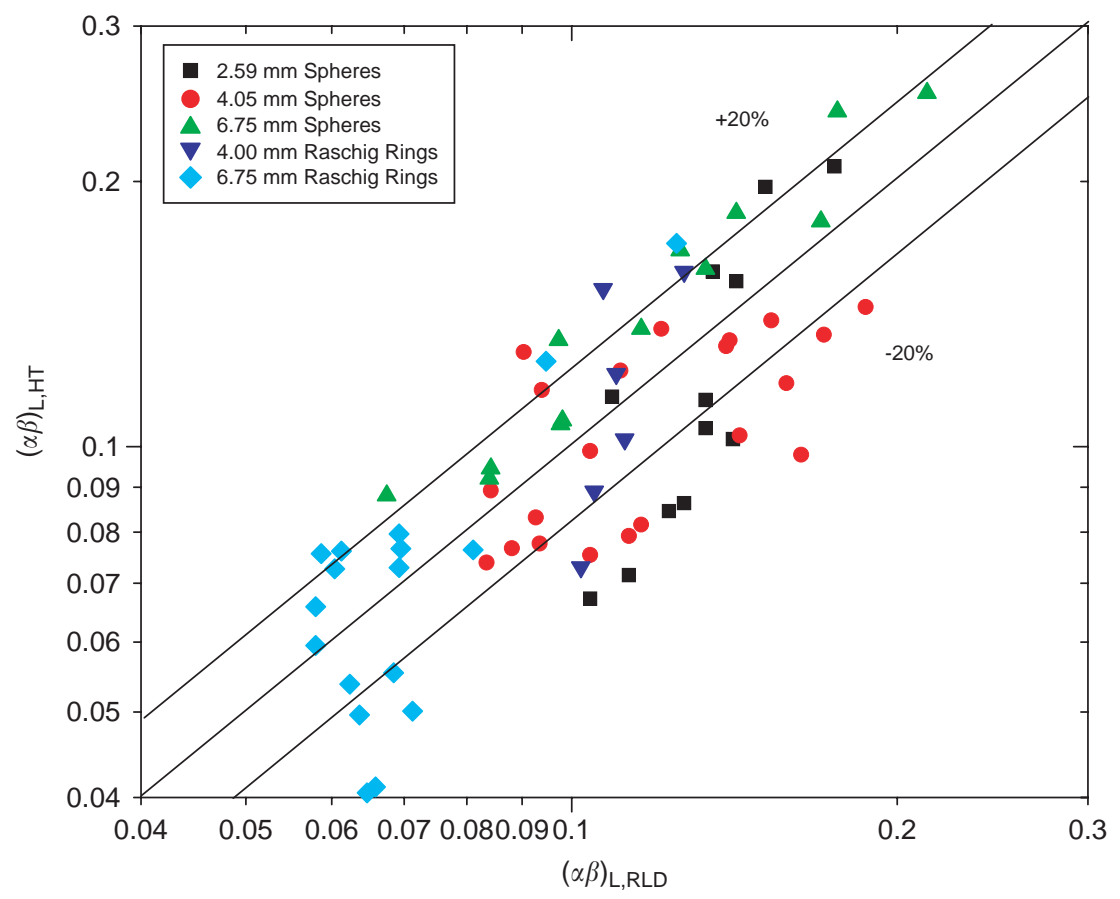

Fig. 2. Comparison of the experimental data of $(\alpha \beta)_{L}$ obtained from heat transfer and radial liquid distribution studies.

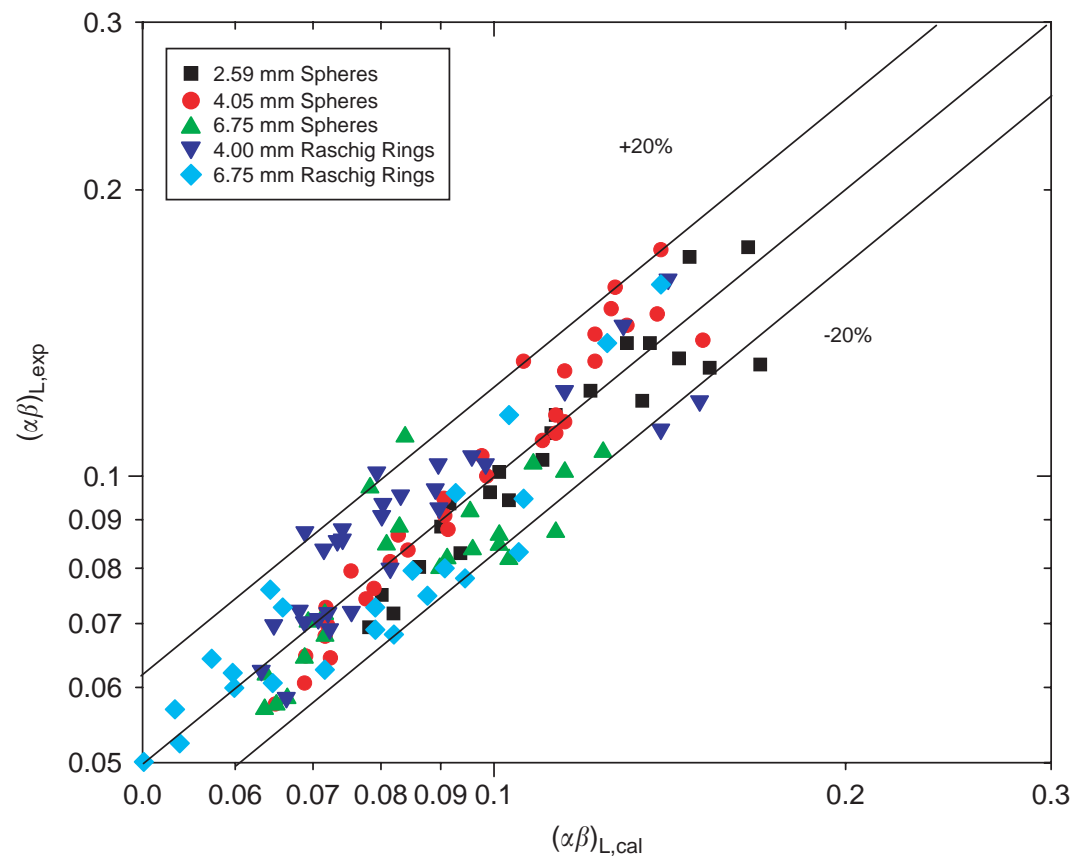

Fig. 3. Comparison of the experimental data of $(\alpha \beta)_{L}$ with the present correlation (Eq. (15)).

time distribution studies using $3 \% \mathrm{NaCl}$ as a tracer by means of a PC-based data acquisition system (Babu, 1993). The total liquid holdup has strong dependence on gas flow rate and hence the effect of gas flow rate is accounted for by two terms in Eq. (15). Hence, it may be noted that $(\alpha \beta)_{L}$ is a strong function of the gas flow rate.
The effect of packing geometry is also incorporated by means of the parameter $a_{s}$ (specific surface area of the packing) in addition to the real liquid and gas velocities in the proposed correlation. Out of the many parameters tried in the present study, $a_{s}$ was found to be the best of all, for the packing geometry (shape and size). 


\section{Comparison of experimental and calculated values from correlation of $(\alpha \beta)_{L}$}

The comparison of $(\alpha \beta)_{L}$ values obtained from experimental studies and that calculated from correlation (Eq. (15)) is shown in Fig. 3. All the data points lie well within the error limits of $\pm 20 \%$ with an s.d. of 0.119 .

\section{Conclusions}

Experiments were carried out to obtain the data on lateral mixing coefficients from both the heat transfer and radial liquid distribution studies, and total liquid holdup over a wide range of gas and liquid rates covering TF, PF and DBF using different size and shape of packings. An expression was derived for $(\alpha \beta)_{L}$ estimation using the data on radial liquid distribution studies. The following conclusions are drawn:

1. Comparison of $(\alpha \beta)_{L}$ values from heat transfer and radial liquid distribution studies shows a good agreement with an s.d. of 0.232 . And around $75 \%$ of the data points lie within the error limits of $\pm 20 \%$. This shows that there exists an analogy between heat transfer and radial liquid distribution in packed beds for both single-phase liquid and two-phase gas-liquid down flow.

2. Taking the importance of $(\alpha \beta)_{L}$ in the estimation of various heat and mass transfer parameters into consideration, a correlation for $(\alpha \beta)_{L}$ based on present heat transfer data is proposed in terms of the operating variables such as real liquid and gas flow rates and specific surface area of packing which effect $(\alpha \beta)_{L}$ the most.

3. Comparison of $(\alpha \beta)_{L}$ estimated from the proposed correlation and the experimental values showed a good agreement with an s.d. of 0.119 and the data being lying well within the error limits of $\pm 20 \%$.

\section{Notation}

$a_{s}$

$A_{i}$

$b_{n}$

$B i$

$c_{p G}^{*}$

$c_{p L}$

$d_{p}$

$D_{e}$

$D_{t}$

$E_{r}$

G

$h_{w}$

$J_{i}$ specific surface area $=6(1-\varepsilon) / d_{p}, \mathrm{~m}^{-1}$

cross-sectional area, $\mathrm{m}^{2}(i=1,2$ and 3 for

central, middle and wall sections)

roots of the Bessel function

Biot number, $h_{w} R / k_{e r}$

specific heat of saturated air, $\mathrm{J} / \mathrm{kg} \mathrm{K}$

specific heat of liquid, $\mathrm{J} / \mathrm{kg} \mathrm{K}$

nominal particle diameter, $\mathrm{m}$

equivalent particle diameter, defined as the di-

ameter of a sphere having the same surface area

to volume ratio as that of a particle, $m$

tube diameter, $\mathrm{m}$

radial mass dispersion coefficient, $\mathrm{m}^{2} / \mathrm{s}$

superficial mass velocity of gas, $\mathrm{kg} / \mathrm{m}^{2} \mathrm{~s}$

wall-to-bed heat transfer coefficient, $\mathrm{W} / \mathrm{m}^{2} \mathrm{~K}$

Bessel function of first kind $(i=0$ and 1 for zero-order and first-order)

\begin{tabular}{|c|c|}
\hline$k_{e o}$ & $\begin{array}{l}\text { effective radial thermal conductivity of the wet } \\
\text { bed under no flow condition, } \mathrm{W} / \mathrm{m} \mathrm{K}\end{array}$ \\
\hline$k_{e r}$ & $\begin{array}{l}\text { effective radial thermal conductivity of the bed } \\
\mathrm{W} / \mathrm{m} \mathrm{K}\end{array}$ \\
\hline$\left(k_{e t}\right)_{G}$ & $\begin{array}{l}\text { effective bed thermal conductivity due to latera } \\
\text { mixing of gas, } \mathrm{W} / \mathrm{m} \mathrm{K}\end{array}$ \\
\hline$\left(k_{e t}\right)_{L}$ & $\begin{array}{l}\text { effective bed thermal conductivity due to latera } \\
\text { mixing of liquid, W/m K }\end{array}$ \\
\hline$k_{L}$ & thermal conductivity of liquid, $\mathrm{W} / \mathrm{m} \mathrm{K}$ \\
\hline$l_{p}$ & $\begin{array}{l}\text { average length between centers of two neighbor- } \\
\text { ing particles in the bed, } m\end{array}$ \\
\hline$L$ & superficial mass velocity of liquid, $\mathrm{kg} / \mathrm{m}^{2} \mathrm{~s}$ \\
\hline $\bar{L}$ & $\begin{array}{l}\text { flow rate of liquid at entrance of test sections } \\
\mathrm{kg} / \mathrm{m}^{2} \mathrm{~s}\end{array}$ \\
\hline $\bar{L}_{i}$ & $\begin{array}{l}\text { flow rate of liquid at exit: } i=1,2,3 \text { for central } \\
\text { middle, wall sections, } \mathrm{kg} / \mathrm{m}^{2} \mathrm{~s}\end{array}$ \\
\hline$n$ & number of data points \\
\hline$P e_{H}$ & $\begin{array}{l}\text { Peclet number of heat transfer for liquid } \\
L c_{p L} d_{p} /\left(k_{e t}\right)_{L}\end{array}$ \\
\hline$P e_{M}$ & $\begin{array}{l}\text { Peclet number of mass transfer for liquid } \\
U_{L} d_{p} / E_{r}\end{array}$ \\
\hline$r$ & radial position \\
\hline$R$ & radius of the column, $\mathrm{m}$ \\
\hline $\operatorname{Re}_{G}$ & Reynolds number for gas, $D_{e} G / \mu_{G}$ \\
\hline $\operatorname{Re}_{L}$ & Reynolds number for liquid, $D_{e} L / \mu_{L}$ \\
\hline$T$ & temperature, ${ }^{\circ} \mathrm{C}$ \\
\hline$T_{\text {cal }}$ & calculated temperature, ${ }^{\circ} \mathrm{C}$ \\
\hline$T_{\exp }$ & experimental temperature, ${ }^{\circ} \mathrm{C}$ \\
\hline$T_{i}$ & inlet temperature, ${ }^{\circ} \mathrm{C}$ \\
\hline$T_{0}$ & outlet temperature, ${ }^{\circ} \mathrm{C}$ \\
\hline$T_{R}$ & temperature at $r=R,{ }^{\circ} \mathrm{C}$ \\
\hline$T_{w}$ & wall temperature, ${ }^{\circ} \mathrm{C}$ \\
\hline$U_{L}$ & superficial velocity of liquid, $\mathrm{m} / \mathrm{s}$ \\
\hline$Z$ & $\left(\operatorname{Re}_{G}\right)^{1.167} /\left(\operatorname{Re}_{L}\right)^{0.767}$ \\
\hline
\end{tabular}

Greek letters

$\alpha$

$\alpha_{i}$

$(\alpha \beta)$

$(\alpha \beta)_{i}$

$(\alpha \beta)_{L, \text { cal }}$

$(\alpha \beta)_{L, \exp }$

$(\alpha \beta)_{L, H T}$

$(\alpha \beta)_{L, R D S}$

$\beta$

$\beta_{t}$

$\varepsilon$

$\mu_{G}$

$\mu_{L}$ fraction of fluid mass velocity moving radially through each of the $N$-planes in a packed bed

fraction of radial spread of liquid ( $i=1,2,3$ for central, middle, wall sections)

lateral mixing coefficient

lateral mixingcoefficient $(i=G$ and $L$ for gas and liquid)

calculated lateral mixing coefficient of liquid

experimental lateral mixing coefficient of liquid

lateral mixing coefficient of liquid from heat transfer studies

lateral mixing coefficient of liquid from radial liquid distribution studies

$l_{p} / d_{p}$

total liquid holdup based on void volume

bed voidage of porosity

viscosity of gas, $\mathrm{kg} /(\mathrm{m} \mathrm{s})$

viscosity of liquid, $\mathrm{kg} /(\mathrm{m} \mathrm{s})$ 


\section{References}

Babu, B.V., 1993. Hydrodynamics and heat transfer in single-phase liquid and two-phase gas-liquid co-current down flow through packed bed columns. $\mathrm{Ph} . \mathrm{D}$. Thesis, Department of Chemical Engineering, I.I.T., Bombay.

Babu, B.V., Rao, V.G., 1998. Prediction of effective bed thermal conductivity and wall-to-bed heat transfer co-efficient in a packed bed under no flow conditions. Journal of Energy, Heat and Mass Transfer 20, 43-50.

Babu, B.V., Rao, V.G., 2007. Thermal resistance models for effective heat transfer parameters in trickle bed reactors. In: Proceedings of Sixth International Symposium on Catalysis in Multiphase Reactors (CAMURE-6) and Fifth International Symposium on Multifunctional Reactors (ISMR-5), NCL-Pune, January 14-17, 2007.

Babu, B.V., Sastry, K.K.N., 1999. Estimation of heat transfer parameters in a trickle bed reactor using differential evolution and orthogonal collocation. Computers and Chemical Engineering 23 (3), 327-339.

Babu, B.V., Shenoy, U.V., Rao, V.G., 1991. Radial liquid distribution studies in trickle-bed columns. In: Proceedings of International Symposium and 44th Annual Session of IIChE (CHEMCON-91), ACCT, Madras, December 18-21, 1991.

Blok, J.R., Drinkenburg, A.A.H., 1982. Hydrodynamics properties of pulses in two-phase down flow operated packed columns. Chemical Engineering Journal 25, 89-99.

Boyer, C., Koudil, A., Chen, P., Dudukovic, M.P., 2005. Study of liquid spreading from a point source in a trickle-bed via gamma-ray tomography and CFD simulation. Chemical Engineering Science 60 (22), 6279-6288.

Charpentier, J.C., 1976. Recent progress in two-phase gas-liquid mass transfer in packed beds. Chemical Engineering Journal 11, 161-181.

De Wasch, A.P., Froment, G.F., 1972. Heat transfer in packed beds. Chemical Engineering Science 27, 567-576.

Gianetto, A., Specchia, B.V., Sicardi, S., 1978. Hydrodynamics and solid-liquid contacting effectiveness in trickle-bed reactors. A.I.Ch.E. Journal 24, 1087-1104.

Hashimoto, K., Muroyama, K., Fujiyoshi, K., Nagata, S., 1976. Effective radial thermal conductivity in co-current flow of a gas and liquid through a packed bed. International Journal of Chemical Engineering 16, 720-727.
Herskowitz, M., Smith, J.M., 1983. Trickle-bed reactors: a review. A.I.Ch.E. Journal 29, 1-18.

Larachi, F., Lamia, B., Ion, I., Bernard, P.A.G., 2003. Heat and mass transfer in co-current gas-liquid packed beds: analysis, recommendations and new correlations. Industrial \& Engineering Chemistry Research 42, 222-242.

Lutran, P.G., Ng, K.M., Delikat, E.P., 1991. Liquid distribution in trickle beds. An experimental study using computer-assisted tomography. Industrial \& Engineering Chemistry Research 30, 1270-1280.

Marcandelli, C., Lamine, A.S., Bernard, J.R., Wild, G., 2000. Liquid distribution in trickle-bed reactor. Oil \& Gas Science and Technology 55, 407-415.

Matsuura, A., Hitaka, Y., Akehata, T., Shirai, T., 1979. Effective radial thermal conductivity in packed beds with gas-liquid down flow. Heat TransferJapanese Research 8 (1), 44-52.

Ranz, W.E., 1952. Friction and transfer coefficient for single particles and packed beds. Chemical Engineering Progress 48, 247-253.

Sato, Y., Hirose, T., Takahashi, F., Toda, M., Hashiguchi, Y., 1973. Flow pattern and pulsation properties of co-current gas-liquid down flow in packed beds. Journal of Chemical Engineering Japan 6, 315-519.

Satterfield, C.N., 1975. Trickle-bed reactors. A.I.Ch.E. Journal 21, 209-228.

Shah, Y.T., 1979. Gas-Liquid-Solid Reactor Design. McGraw Hill International Book Company, New York.

Specchia, V., Baldi, G., 1979. Heat transfer in trickle-bed reactors. Chemical Engineering Communication 3, 483-499.

Specchia, V., Baldi, G., Sicardi, S., 1980. Heat transfer in packed bed reactors with one phase flow. Chemical Engineering Communication 4, 361-380.

Tsang, T.H., Edgar, T.F., Hougen, J.O., 1976. Estimation of heat transfer parameters in a packed bed. Chemical Engineering Journal 11, 57-66.

Yagi, S., Kunii, D., 1957. Studies on effective thermal conductivities in packed beds. A.I.Ch.E. Journal 3, 372-381.

Yagi, S., Kunii, D., Endo, K., 1964. Heat transfer in packed beds through which water is flowing. International Journal of Heat Mass Transfer 7, 333-339. 